\title{
Discovery of Eriodictyol as Putative Exportin-1 Inhibitor for Non-small Cell Lung Cancer Therapy
}

Temidayo Olamide Adigun ${ }^{1 *}$, Ireoluwa Yinka Joel ${ }^{1}$, Olukayode Olusola Bankole ${ }^{1,2}$, Ambrose Oche George ${ }^{1}$, Oluwatobi Ayodeji Medayedupin ${ }^{1}$, Oluwatobi Cynthia Omoyeni ${ }^{2}$, Adebimpe Ayomide Agunlejika ${ }^{2}$, Ugochukwu Okechukwu Ozojiofor ${ }^{3}$, Adedayo Pius Omoniyi ${ }^{4}$, Idowu Yetunde Fakolujo ${ }^{1}$

Corresponding author: prothesis4life@gmail.com (Temidayo Olamide Adigun)

${ }^{1}$ Department of Biochemistry, Faculty of Life Sciences, University of Ilorin, Ilorin, Nigeria

${ }^{2}$ Department of Science and Laboratory Technology, School of Pure and Applied Sciences, Federal Polytechnic Ilaro

${ }^{3}$ Department of Biotechnology, Nigeria Defence Academy, Kaduna, Nigeria

${ }^{4}$ Department of Biochemistry, School of Science, Federal University of Technology Akure, Akure, Nigeria

\begin{abstract}
Exportin-1, the ubiquitous nuclear protein transporter, is widely confirmed as an active chemotherapeutic target in non-small cell lung cancer condition while Juglans mandshurica is a well-studied anticancer plant in some lung cancer cell lines. We intend to find novel exportin-1 inhibitor from Juglans mandshurica with better potential tolerability and pharmaco-dynamokinetic properties than the current selective inhibitors of nuclear export in non-small cell lung cancer treatment. Osiris property explorer DataWarrior, Glide standard precision docking, quantum mechanics polarized ligand docking, MMGBSA binding free energy calculations, Jaguar density functional theory analysis, and the online web-based SwissADME were employed respectively in this study to filter the retrieved compounds based on tolerability, toxicity, and Lipinsky's rule of five violation potential, determine their druggability, establish relative stability of the lead compound in water solvation model, and evaluates druglikeness, lead-likeness, as well as synthetic accessibility of the lead compound. This study reveals eriodictyol as having higher binding free energy $(-40 \mathrm{kcal} / \mathrm{mol})$ than that of standard $(-39.56 \mathrm{kcal} / \mathrm{mol})$ in exportin- 1 active site, better synthetic accessibility score (3.15 versus 3.29), high GI absorption, non-blood brain barrier permeant, lacks Brenk and PAINS alert, obeying Lipinski's, Ghose's, Veber's, Egan's, and
\end{abstract}


Muegge's rule of druglikeness and lead-likeness as well as non-cytotoxic to HepG2 cells. We therefore found eriodictyol as a lead-like, non-toxic exportin-1 inhibitor with good predictive stability and pharmacokinetic potential and thus provided data for further validation of eriodictyol as a candidate exportin-1 inhibitor in both preclinical and clinical studies involving lung cancer therapy.

Keywords: Exportin-1, Eriodictyol, Juglans mandshurica, Non-small cell lung cancer

\subsection{Introduction}

Exportin-1 (XPO-1), also known as chromosomal region maintenance 1 (CRM 1), is an essentially active ubiquitous exporter of more than 1050 protein cargoes from human cell nucleus to cytoplasm according to recent deep proteomic characterization studies of nucleocytoplasmic organization of eukaryotic cells (Kirli et al., 2015; Zhu et al., 2019). It recognizes leucine-rich signals on intranuclear cargo proteins containing tumour suppressor proteins (such as p53, p73, p21, p27 etc.) and other cell cycle regulators (such as retinoblastoma, adenomatous polyposis coli, forkhead box $\mathrm{O}$, activator of transcription 3, inhibitor of kappa B-alpha, protease-activated receptor 4, topoisomerase II, galectin-3 etc.) and mediates their RanGTP-driven transport into cytoplasm (Sun et al., 2014; Sun et al., 2016).

Exportin-1 carries out this active process in a regulatory way under normal physiological conditions but becomes dysregulated, via overexpression, in cancer conditions (Wang and Liu, 2019). This drive oncogenic features such as aberrant growth signaling, apoptosis inactivation, angiogenesis sustenance as well as its association with drug resistance (due to excessively dislocated drug targets such as topoisomerase II, galectin-3 etc.) in non-small cell lung cancer (NSCLC), including the highly untreatable KRAS-mutant lung adenocarcinoma (Sun et al., 2014). Exportin-1 is frequently amplified and/or mutated (e.g. the clinically relevant gain-of-function mutation such as E571K and R749Q) with its over-expression correlating with poor prognosis in NSCLC patients (Gupta et al., 2017; Zhu et al., 2019). Targeting XPO1 alone by the recently developed selective inhibitors of nuclear export (SINE) (e.g. the widely studied KPT-330 (selinexor), KPT-185, KPT-225, KPT-276 etc.) or in combination with other targeted therapies or 
chemotherapies have shown broad anticancer effect and acceptable tolerance (Wang et al., 2014; Zhu et al., 2019).

Although several orally bioavailable inhibitors of XPO1 has been developed, with many of them currently showing promising efficacy whether as a single anticancer agent or synergistically in combination regimens under clinical trials (Gupta et al., 2017; Azizian and Li, 2020); their effects remains limited by their low safety profiles including the brain-associated adverse effects like anorexia, weight loss etc. as well as haematologic adverse effects such as thrombocytopaenia (Zhu et al., 2019; Azizian and Li, 2020). These have been associated respectively with the blood brain barrier penetrability and the off-target effects of some of these inhibitors, with reduced tolerability in cancer patients (Azizian and Li, 2020). Also, KPT-185 has been shown to possess unsuitable pharmacokinetic properties in vivo, either subcutaneously or orally in a pre-clinical study (Zhang et al., 2013).

We aim to find out in this study whether there is a better potential selective inhibitor (s) of nuclear export (SINE) among the various compounds identified and isolated from Juglans mandshurica in some reports (Guo et al., 2015; Luo et al., 2017; Jahaban-Esfahlan et al., 2019). Also, we aim to determine whether these potential inhibitor (s) may have better predictive tolerability and suitable pharmacokinetic properties than the currently known SINE compounds for treating nonsmall cell lung cancer condition.

Several drug entities from nature (the master craftsman of molecules) have been used to cure various ailments since the inception of first known human civilization while plants remain an infinite resource harbouring promising novel chemotypic drug development against cancer (Veeresham, 2012; Wannes et al., 2018). Indeed, several current standard-of-care drugs (with relatively few side effects) are known to have been developed from plants such as the alkaloids vinblastine (from Catharanthus roseus), paclitaxel (from Taxus brevifolia) while more phytochemicals are showing great promises for cancer prevention and treatment in many preclinical and clinical studies (Zhang et al., 2015; Asadi-Samani et al., 2016; Wannes et al., 2018).

\subsection{Methods}

\subsection{Target preparation}

The PDB coordinate files (PDB ID: 3GB8) of human (homo sapiens) crystal structure of chromosomal region maintenance 1 (CRM 1)-Snurportin-1 complex was 
retrieved from the protein data bank (http://www.rcsb.org), visualized using the Schrodinger molecular graphics program PyMol® and prepared using Schrodinger maestro protein preparation wizard. Briefly, the Snuportin-1 chain (chain B) was deleted from the complex while the remainder (chain A) was prepared under OPLS2005 force field at $\mathrm{pH}$ of 7.0 2 2.0. All steric clashes were corrected, hydrogen bond order fixed while the missing side chains and loops were corrected using prime. Disulfide bonds were created, water molecules beyond $5.00 \AA$ were removed from the ionized (Het) groups, waters with less than 3 hydrogen bonds to non-waters were deleted while the bond orders were assigned. The charge cutoff for polarity was 0.25 .

\subsection{Ligand Preparation}

We retrieved the two-dimensional structures of compounds identified and isolated from various parts and extracts of Juglans mandshurica in some studies (Guo et al., 2015; Luo et al., 2017; Jahaban-Esfahlan et al., 2019) while the structures of compounds unavailable in PubChem database were designed using ChemAxon Marvin sketch. All the compounds were converted into 3D SDF format before being filtered based on Lipinsky's rule, total polar surface area (TPSA) $\leq$ $140 \AA$ as well as number of rotatable bonds $\leq 10$, using DataWarrior v 5.2.1 of Osiris property explorer to retain those that meet these criteria. These were, in addition, prefiltered based on their tumorigenicity, mutagenicity, irritant properties, nasty functions, druglikeness, molecular flexibility and complexity. The ligands were prepared using Schrodinger maestro ligand preparation wizard. Briefly, the ligands were desalted, possible epik states and tautomers were generated at the target $\mathrm{pH}$ of $7.0 \pm 2.0$, specified chirality were retained while other chiral centers were varied.

\subsection{Ligand Docking}

Sampled flexible ligand (based on nitrogen inversion and ring conformations) were docked into target sitemap-generated receptor grid using Glide standard precision docking procedure and post docking minimization were performed. Input partial charges were used in calculating the docking score while the ligand with more than 500 atoms was excluded from docking nor scored. The van der Waals radii of ligand atoms with partial atomic charge were scaled with factor of 0.80 less than the partial charge cut-off of 0.15 and the Epik state penalties were added to the docking score. 


\subsection{Quantum Mechanics Polarized Ligand Docking}

The ligand charges for the initial Glide docking were generated using the standard semiempirical method precision in which the pose was discarded as duplicate if both root mean square deviation is less than $0.5 \AA$ and the maximum atomic displacement is less than $1.3 \AA$. The quantum mechanics charges were calculated for free ligands in the gas phase using the Coulson charge semi empirical method before redocking at standard precision. Ligands, with their best binding pose, were finally selected based on the GlideScore while the van der Waals scaling was at 1.0 and 0.8 respectively for the receptor and ligand.

\subsection{Validation of Docking Study}

The docking protocol of this study was validated by redocking of the same standard compound into the same target binding site and examining the relative binding pose of the ligands using the Python Molecular Viewer (PyMol®) graphics software while the docking scores was validated by docking both the lead and standard compound with different docking algorithms including Molegro virtual docking program (based on rerank score calculated from both MolDock and PLANTS scoring function), Argus Lab (based on AScore scoring function at the best ligand pose), PyRx Autodock Vina (based on Vina scoring function) as well as the online web-based SwissDock (based on evolutionary algorithm docking scoring function).

\subsection{Binding Free Energy Calculation}

Prime was used to calculate the molecular mechanics generalized born surface area free energy change (MMGBSA dG) of the docked ligands by considering the input ligand partial charges on the VSGB solvation model. Constraints were applied on the flexible residues and their distances were defined using all processed ligands.

\subsection{Target-Ligand Interaction Representation}

The docked ligands in complex with the targets and their respective binding poses were generated using Glide merging procedure while the two-dimensional interactions between the ligands and 
the target binding pocket residues were visualized using BIOVIA discovery studio suite and PyMol® respectively.

\subsection{Density Functional Theory Analysis}

The molecular orbital energy (represented by HOMO, LUMO, and gap energy), atomic electrostatic potential energy (ESP), and vibrational frequencies of the compounds were calculated by using Jaguar single point energy estimator in water solvation model (having dielectric constant of 80.37).

\subsection{In-silico Pharmacokinetics and Toxicity Properties Profiling}

The resultant lead compounds from this study were profiled for their absorption, distribution, metabolism, excretion, and toxicity properties by using the web-based predictive tool SwissADME (http://www.swissadme.ch/index.php).

\subsection{Results and Discussion}

\subsection{Compounds Retrieved}

The total of 133 compounds reported by some studies (Guo et al., 2015; Luo et al., 2017; JahabanEsfahlan et al., 2019) were retrieved in this study while a total of 22 (Table 1) with predictably non-toxic and drug-like compounds were recovered following the pre-filtering workflow (See 2.2) on Osiris property explorer. Compound A-F, Y, Z were the identified but non-designated compounds from Juglans mandshurica with currently no structural information in the PubChem database while the first-generation SINE compound KPT-185 (PubChem CID: 53495165) was evaluated as the standard compound.

Table 1: The Retrieved Compounds and their Simplified Molecular Input Line Entry System

Representation Following Drug-likeness and Toxicity Filters

\begin{tabular}{|c|c|c|}
\hline S/N & COMPOUND & CANONICAL SMILES \\
\hline 1 & 3-Methoxyjuglone & $\mathrm{O}=\mathrm{C} 1 \mathrm{c} 2 \mathrm{c}(\mathrm{O}) \operatorname{cccc} 2 \mathrm{C}(=\mathrm{O}) \mathrm{C}=\mathrm{C} 1 \mathrm{OC}$ \\
\hline 2 & O-Methyljuglone & $\mathrm{O}=\mathrm{C} 1 \mathrm{c} 2 \mathrm{c}(\mathrm{OC}) \mathrm{cccc} 2 \mathrm{C}(=\mathrm{O}) \mathrm{C}=\mathrm{C} 1$ \\
\hline 3 & Compound A & $\mathrm{O}=\mathrm{C} 1 \mathrm{c} 2 \mathrm{c}(\mathrm{O}) \operatorname{cccc} 2 \mathrm{C}(=\mathrm{O}) \mathrm{C} 2=\mathrm{C} 1 \mathrm{C} 1(\mathrm{O}) \mathrm{c} 3 \mathrm{c}(\mathrm{C}(=\mathrm{O})[\mathrm{C} @ @ \mathrm{H}] 2 \mathrm{C} 1) \mathrm{c}(\mathrm{O}) \mathrm{ccc} 3$ \\
\hline
\end{tabular}




\begin{tabular}{|c|c|c|}
\hline 4 & Isosclerone & $\mathrm{O}=\mathrm{C} 1 \mathrm{c} 2 \mathrm{c}(\mathrm{O}) \operatorname{ccc} 2[\mathrm{C} @ \mathrm{H}](\mathrm{CC} 1) \mathrm{O}$ \\
\hline 5 & Sclerone & $\mathrm{O}=\mathrm{C} 1 \mathrm{c} 2 \mathrm{c}(\mathrm{c}(\mathrm{O}) \mathrm{ccc} 2)[\mathrm{C} @ \mathrm{H}](\mathrm{CC} 1) \mathrm{O}$ \\
\hline 6 & Compound B & $\mathrm{O}=\mathrm{C} 1 \mathrm{c} 2 \mathrm{c}(\mathrm{O}) \operatorname{ccc} 2 \mathrm{C} 2(\mathrm{CC} 1 \mathrm{C}(\mathrm{c} 1 \mathrm{c} 2 \mathrm{cc}(\mathrm{c}(\mathrm{c} 1) \mathrm{O}) \mathrm{O}) \mathrm{CC}(=\mathrm{O}) \mathrm{O}) \mathrm{O}$ \\
\hline 7 & Compound $\mathrm{C}$ & Br.Oc1c $(\operatorname{cccc} 1) \mathrm{C} 12 \mathrm{C}(\mathrm{N}(\mathrm{C}(\mathrm{C} 2) \mathrm{CCC} 1) \mathrm{C}) \mathrm{C}$ \\
\hline 8 & Caffeic acid & $\mathrm{O}=\mathrm{C}(\mathrm{O}) / \mathrm{C}=\mathrm{C} / \mathrm{c} 1 \mathrm{cc}(\mathrm{O}) \mathrm{c}(\mathrm{cc} 1) \mathrm{O}$ \\
\hline 9 & Ferrulic acid & $\mathrm{O}=\mathrm{C}(\mathrm{O}) / \mathrm{C}=\mathrm{C} / \mathrm{c} 1 \mathrm{cc}(\mathrm{OC}) \mathrm{c}(\mathrm{cc} 1) \mathrm{O}$ \\
\hline 10 & P-Coumaric acid & $\mathrm{O}=\mathrm{C}(\mathrm{O}) / \mathrm{C}=\mathrm{C} / \mathrm{c} 1 \mathrm{ccc}(\mathrm{cc} 1) \mathrm{O}$ \\
\hline 11 & Sinapic acid & $\mathrm{O}=\mathrm{C}(\mathrm{O}) / \mathrm{C}=\mathrm{C} / \mathrm{c} 1 \mathrm{cc}(\mathrm{OC}) \mathrm{c}(\mathrm{c}(\mathrm{c} 1) \mathrm{OC}) \mathrm{O}$ \\
\hline 12 & L-Epicatechin & $\mathrm{O} 1 \mathrm{c} 2 \mathrm{c}(\mathrm{c}(\mathrm{O}) \mathrm{cc}(\mathrm{c} 2) \mathrm{O}) \mathrm{CC}(\mathrm{C} 1 \mathrm{c} 1 \mathrm{cc}(\mathrm{O}) \mathrm{c}(\mathrm{cc} 1) \mathrm{O}) \mathrm{O}$ \\
\hline 13 & Eriodictyol & $\mathrm{O}=\mathrm{C} 1 \mathrm{c} 2 \mathrm{c}(\mathrm{O}[\mathrm{C} @ @ \mathrm{H}](\mathrm{C} 1) \mathrm{c} 1 \mathrm{cc}(\mathrm{O}) \mathrm{c}(\mathrm{cc} 1) \mathrm{O}) \mathrm{cc}(\mathrm{cc} 2 \mathrm{O}) \mathrm{O}$ \\
\hline 14 & $\begin{array}{c}\text { Epidihydrophaseic } \\
\text { acid }\end{array}$ & $\mathrm{O}=\mathrm{C}(\mathrm{O}) / \mathrm{C}=\mathrm{C}(/ \mathrm{C}=\mathrm{C} / \mathrm{C} 1(\mathrm{O}) \mathrm{C} 2(\mathrm{OCC} 1(\mathrm{CC}(\mathrm{C} 2) \mathrm{O}) \mathrm{C}) \mathrm{C}) \backslash \mathrm{C}$ \\
\hline 15 & L-Ascorbic acid & $\mathrm{O}=\mathrm{C} 1 \mathrm{O}[\mathrm{C} @ @ \mathrm{H}](\mathrm{C}(=\mathrm{C} 1 \mathrm{O}) \mathrm{O}) \mathrm{C}(\mathrm{O}) \mathrm{CO}$ \\
\hline 16 & $\begin{array}{c}\text { 1(2H)- } \\
\text { Naphthalenone }\end{array}$ & $\mathrm{O}=\mathrm{C} 1 \mathrm{c} 2 \mathrm{c}(\mathrm{cccc} 2)[\mathrm{C} @ \mathrm{H}](\mathrm{CC} 1) \mathrm{O}$ \\
\hline 17 & $\begin{array}{l}\text { (4S)-4alpha- } \\
\text { Methoxy-S- } \\
\text { Hydroxytetralin- } \\
\text { 1-one }\end{array}$ & $\mathrm{O}=\mathrm{C} 1 \mathrm{c} 2 \mathrm{c}(\mathrm{c}(\mathrm{O}) \mathrm{ccc} 2)[\mathrm{C} @ \mathrm{H}](\mathrm{CC} 1) \mathrm{OC}$ \\
\hline 18 & Compound D & $\mathrm{O}=\mathrm{C} 1 \mathrm{c} 2 \mathrm{c}(\mathrm{c}(\mathrm{O}) \mathrm{ccc} 2)[\mathrm{C} @ \mathrm{H}](\mathrm{CC} 1) \mathrm{O} . \mathrm{Oc} 1 \mathrm{cccc} 1$ \\
\hline 19 & Compound E & $\mathrm{O}=\mathrm{C} 1 \mathrm{c} 2 \mathrm{c}(\mathrm{O}) \mathrm{ccc}(\mathrm{c} 2[\mathrm{C} @ \mathrm{H}](\mathrm{CC} 1) \mathrm{OC}) \mathrm{O} . \mathrm{Oc} 1 \mathrm{cccc} 1$ \\
\hline 20 & Compound F & $\mathrm{O}=\mathrm{C} 1 \mathrm{c} 2 \mathrm{c}(\mathrm{c}(\mathrm{O}) \mathrm{ccc} 2)[\mathrm{C} @ \mathrm{H}](\mathrm{CC} 1) \mathrm{OC} \cdot \mathrm{Oc} 1 \mathrm{cccc} 1$ \\
\hline 21 & Compound $\mathbf{Y}$ & $\mathrm{O}=\mathrm{C} 1 \mathrm{c} 2 \mathrm{c}(\mathrm{O}) \operatorname{ccc} 2 \mathrm{C}(\mathrm{CC} 1) \mathrm{OC} 1 \mathrm{c} 2 \mathrm{c}(\mathrm{O}) \operatorname{ccc} 2 \mathrm{C}(=\mathrm{O}) \mathrm{CC} 1$ \\
\hline 22 & Compound $\mathrm{Z}$ & $\mathrm{O}=\mathrm{C} 1 \mathrm{c} 2 \mathrm{c}(\mathrm{O}) \operatorname{ccc} 2 \mathrm{C}(\mathrm{CC} 1) \mathrm{OC} 1 / \mathrm{C}(=\mathrm{C} / \mathrm{O}) / \mathrm{C}(=\mathrm{C} / \mathrm{O}) / \mathrm{C}(=\mathrm{O}) \mathrm{CC} 1$ \\
\hline
\end{tabular}

Complex balance exists between the molecular weight and other descriptors defining the oral bioavailability and bioactivity of compounds. Increased molecular weight positively associates with high bioactivity at the target site but tend toward less bioavailability due to its reduced permeability potential (Veber et al., 2002; Ratomir et al., 2016). Hence the general consensus for predictably bioavailable and drug-like compounds have been modelled on the range of $160 \leq$ molecular weight $<500$ (Lipinski et al., 2001; Ghose et al., 1999). The 22 compounds retrieved in this study fulfilled this requirement (Table 2) by having molecular weights ranging from 162.19 to 356.33 . 
The water-octanol partition coefficient $(\mathrm{ClogP})$ is a well-recognized metric point value of a compound lipophilicity with defining impact on the drug bioavailability. The calculated $\log \mathrm{P}$ (ClogP) of retrieved compounds in this study (Table 2) falls within the range of -3.1715 to 2.4646. Furthermore, other physicochemical properties of the compounds including hydrogen bond acceptors (2-7) and donors (0-5) counts, rotatable bond counts (0-4) and total polar surface area (23.47-135.29) obey the Veber et al. (2002) and Muegge et al. (2001) drug-like model.

Table 2: Physicochemical Properties of Retrieved Compounds

\begin{tabular}{|c|c|c|c|c|c|c|c|}
\hline $\mathbf{S} / \mathbf{N}$ & Molecule Name & $\begin{array}{c}\text { Molecular } \\
\text { weight }\end{array}$ & $\mathrm{Clog} P$ & $\begin{array}{c}\text { H- } \\
\text { Acceptors }\end{array}$ & $\begin{array}{c}\text { H- } \\
\text { Donors }\end{array}$ & $\begin{array}{c}\text { Polar } \\
\text { Surface } \\
\text { Area }(\AA)\end{array}$ & $\begin{array}{c}\text { Rotatable } \\
\text { Bonds }\end{array}$ \\
\hline 1 & 3-Methoxyjuglone & 204.181 & 1.0218 & 4 & 1 & 63.6 & 1 \\
\hline 2 & O-Methyljuglone & 188.182 & 1.3694 & 3 & 0 & 43.37 & 1 \\
\hline 3 & Compound A & 348.309 & 1.8755 & 6 & 3 & 111.9 & 0 \\
\hline 4 & Isosclerone & 178.186 & 1.1939 & 3 & 2 & 57.53 & 0 \\
\hline 5 & Sclerone & 178.186 & 1.1939 & 3 & 2 & 57.53 & 0 \\
\hline 6 & Compound B & 356.329 & 1.6467 & 7 & 5 & 135.29 & 2 \\
\hline 7 & Compound $\mathrm{C}$ & 312.25 & 2.5243 & 2 & 1 & 23.47 & 1 \\
\hline 8 & Caffeic acid & 180.159 & 0.7825 & 4 & 3 & 77.76 & 2 \\
\hline 9 & Ferrulic acid & 194.185 & 1.0582 & 4 & 2 & 66.76 & 3 \\
\hline 10 & P-Coumaric acid & 164.16 & 1.1282 & 3 & 2 & 57.53 & 2 \\
\hline 11 & Sinapic acid & 224.211 & 0.9882 & 5 & 2 & 75.99 & 4 \\
\hline 12 & L-Epicatechin & 290.27 & 1.5087 & 6 & 5 & 110.38 & 1 \\
\hline 13 & Eriodictyol & 288.254 & 1.81 & 6 & 4 & 107.22 & 1 \\
\hline 14 & $\begin{array}{c}\text { Epidihydrophaseic } \\
\text { acid }\end{array}$ & 282.335 & 1.0554 & 5 & 3 & 86.99 & 3 \\
\hline 15 & L-Ascorbic acid & 176.124 & -2.4646 & 6 & 4 & 107.22 & 2 \\
\hline 16 & $\begin{array}{c}\text { 1(2H)- } \\
\text { Naphthalenone }\end{array}$ & 162.187 & 1.5396 & 2 & 1 & 37.3 & 0 \\
\hline 17 & $\begin{array}{l}\text { (4S)-4alpha- } \\
\text { Methoxy-S- }\end{array}$ & 192.213 & 1.6218 & 3 & 1 & 46.53 & 1 \\
\hline
\end{tabular}




\begin{tabular}{|c|c|c|c|c|c|c|c|}
\hline & $\begin{array}{c}\text { Hydroxytetralin- } \\
\text { 1-one }\end{array}$ & & & & & \\
\hline 18 & Compound D & 272.299 & 1.1939 & 3 & 2 & 57.53 & 0 \\
\hline 19 & Compound E & 302.325 & 1.2761 & 4 & 2 & 66.76 & 1 \\
\hline 20 & Compound F & 286.326 & 1.6218 & 3 & 1 & 46.53 & 1 \\
\hline 21 & Compound Y & 338.358 & 3.1715 & 5 & 2 & 83.83 & 2 \\
\hline 22 & Compound Z & 330.335 & 0.9801 & 6 & 3 & 104.06 & 2 \\
\hline
\end{tabular}

The druglikeness score (QED), quantifying the overall contribution of physicochemical and toxicity properties, is a useful metric for a compound potential as drug candidate. The prefiltered 22 compounds showed predictive toxicity level of none (no risk) to low (low risk) (Table 3) for tumorigenicity, mutagenicity, teratogenicity and irritant properties with quantitative estimate of druglikeness (druglikeness score) range of -1.3232 to 1.9964 in this study. Although the positive druglikeness scores help qualifies the compounds as containing predominantly fragments frequently present in current commercially available drugs; this, however, may sometimes be representative of few physicochemical descriptors and therefore contributes only partially toward druglike potential of the compounds (López-López et al., 2019).

Table 3: Toxicity Profile and Drug-likeness Score of Retrieved Compounds

\begin{tabular}{|c|c|c|c|c|c|c|}
\hline S/N & Molecule Name & Mutagenic & Tumorigenic & $\begin{array}{c}\text { Reproductive } \\
\text { Effectiveness }\end{array}$ & Irritant & QED \\
\hline 1 & 3-Methoxyjuglone & none & none & none & none & 0.6467 \\
\hline 2 & O-Methyljuglone & none & none & none & none & 0.33786 \\
\hline 3 & Compound A & none & none & none & none & 1.3461 \\
\hline 4 & Isosclerone & none & none & none & none & -1.0249 \\
\hline 5 & Sclerone & none & none & none & none & -1.0249 \\
\hline 6 & Compound B & none & none & low & none & 0.75027 \\
\hline 7 & Compound C & none & none & none & none & 1.2862 \\
\hline 8 & Caffeic acid & none & none & none & none & 0.1675 \\
\hline 9 & Ferrulic acid & none & none & none & none & 0.27506 \\
\hline
\end{tabular}




\begin{tabular}{|c|c|c|c|c|c|c|}
\hline 10 & P-Coumaric acid & none & none & none & none & 0.1675 \\
\hline 11 & Sinapic acid & none & none & none & none & 0.27506 \\
\hline 12 & L-Epicatechin & none & none & none & none & 0.31525 \\
\hline 13 & Eriodictyol & none & none & none & none & -0.22006 \\
\hline 14 & $\begin{array}{c}\text { Epidihydrophaseic } \\
\text { acid }\end{array}$ & none & none & none & none & 1.9964 \\
\hline 15 & L-Ascorbic acid & none & none & none & none & 0.023806 \\
\hline 16 & $\begin{array}{c}\text { 1(2H)- } \\
\text { Naphthalenone }\end{array}$ & none & none & none & none & -1.0249 \\
\hline 17 & $\begin{array}{c}\text { (4S)-4alpha- } \\
\text { Methoxy-S- } \\
\text { Hydroxytetralin- } \\
\text { 1-one }\end{array}$ & none & none & none & none & -1.1964 \\
\hline 18 & Compound D & none & none & none & none & -1.0249 \\
\hline 19 & Compound E & none & none & none & none & -1.1964 \\
\hline 20 & Compound F & none & none & none & none & -1.1964 \\
\hline 21 & Compound Y & none & none & none & none & -1.3232 \\
\hline 22 & Compound Z & none & none & none & none & -0.29045 \\
\hline
\end{tabular}

The complexity score of a compound is a defining feature on its solubility, permeability, oral bioavailability, promiscuity, as well as, in consequence, its clinical efficacy. It accounts for its number of aromatic rings, fraction of $\mathrm{sp}^{3}$ hybridized carbons $\left(\mathrm{Fsp}^{3}\right)$, and negatively correlates with the compound developability and safety profile (Lagorce et al., 2017). The molecular complexity score of the 22 retrieved compounds in this study is in the range of 0.50742 to 1.0424 on a scale of $0.1-1.5$.

The ligand conformational flexibility score, a measure of diverse assumable shapes based on molecular complexity score, dihedral bond angle changes and geometry weighting factors, plays pivotal role on its binding affinity and specificity to the target (Arteca, 1993; Forrey et al., 2012). The molecular flexibility score (Figure 1) of the 22 retrieved compounds in this study is in the range of 0.08271 to 0.50646 on a scale of 0.0 (flexible) to 1.0 (completely rigid). 


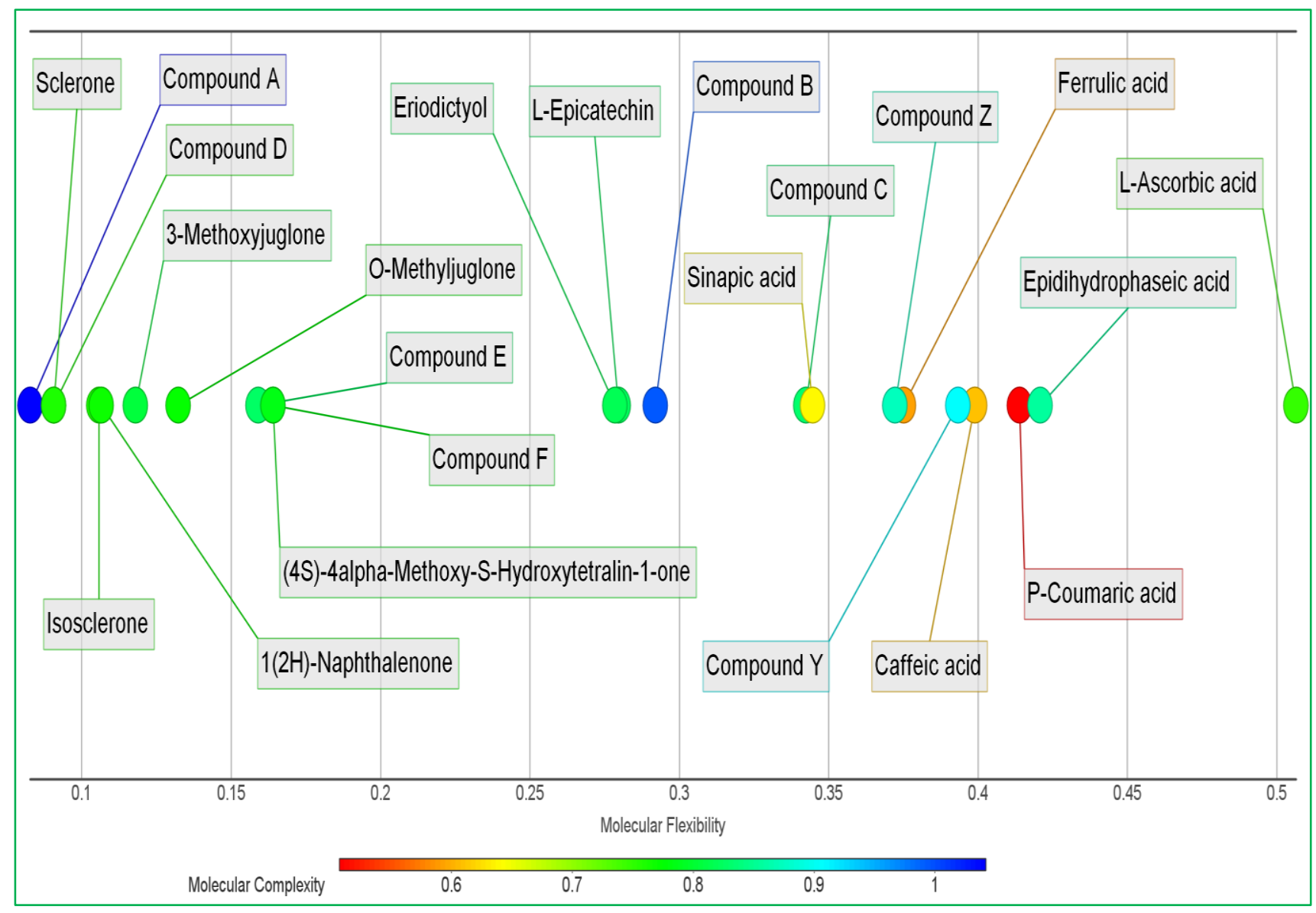

Figure 1: Flexibility and Complexity Scores of Retrieved Compounds

\subsection{Ligand Docking}

The recent development of exportin-1 inhibitors has excluded the overexpressed protein from orphan receptor category in NSCLC therapeutic strategies, but limitations abound around the efficacy, potency, and safety of these drug entities. This, therefore, predates the need for discovery and development of better new drug-like molecule entity. The Glide virtual screening of retrieved drug-like Juglans mandshurica compounds against exportin-1 structure coordinate files in this study revealed L-epicatechin, epidihydrophaseic acid as having relatively higher binding free energy and eriodictyol having binding free energy at very close range $(-34.51 \mathrm{kcal} / \mathrm{mol}$ to $34.9 \mathrm{kcal} / \mathrm{mol}$ ) when compared to $-34.9 \mathrm{kcal} / \mathrm{mol}$ of the standard compound (KPT-185) as the benchmark score. This suggest the potential relatively higher affinity, and in consequence, efficacy of these hits at the exportin-1 active site. 


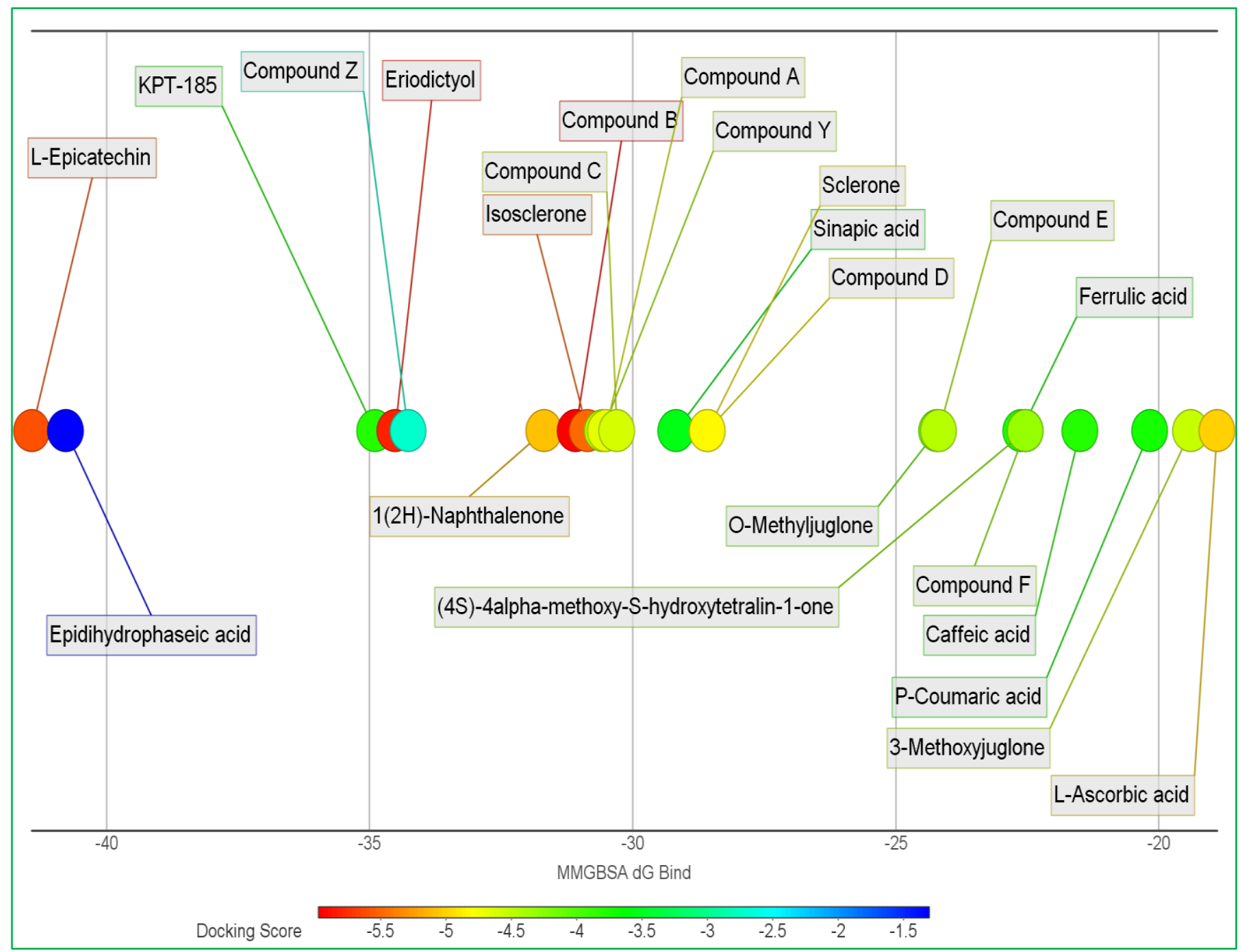

Figure 2: Graphical Representation of Docking Score and MMGBSA dG Binding of Retrieved Compounds following Glide Standard Precision Ligand Docking

\subsection{Quantum Mechanics Polarized Ligand Docking}

The atomic valence electrons are always in motion around the molecule (Duan et al., 2020). Therefore, considering the partial charges being contributed by each compound fragments to binding affinity at the target binding site has proven to be effective means toward accurate binding free energy calculations. This is done by applying the plausible target residue-ligand charge polarization in the calculation of the ligand binding energy at the best possible conformation. This 
returned only eriodictyol (Figure 3), having binding free energy of $-40 \mathrm{kcal} / \mathrm{mol}$ against $39.56 \mathrm{kcal} / \mathrm{mol}$ of KPT-185, as the putative lead drug-like exportin-1 inhibitor in this study.

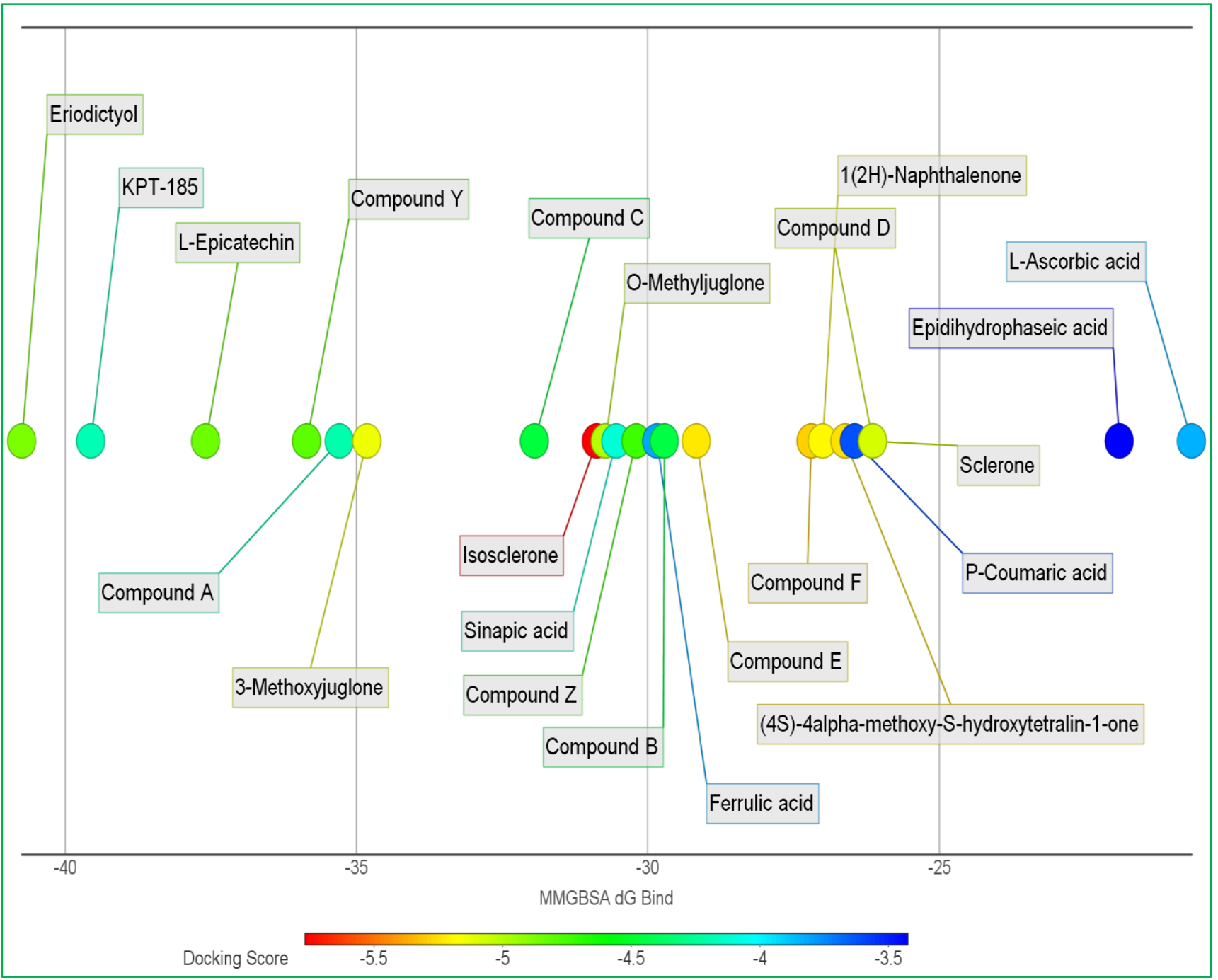

Figure 3: Graphical Representation of Docking Score and MMGBSA dG Binding of Retrieved Compounds following Quantum Polarized Ligand Docking

\subsection{Study Validation}

The superimposition of conformational binding poses of the redocked KPT-185 at the exportin-1 active site (Figure 4) in this study shows positive validity of the ligand docking procedure while the results from other docking algorithms (Table 4) further confirmed this study Glide docking scores. 


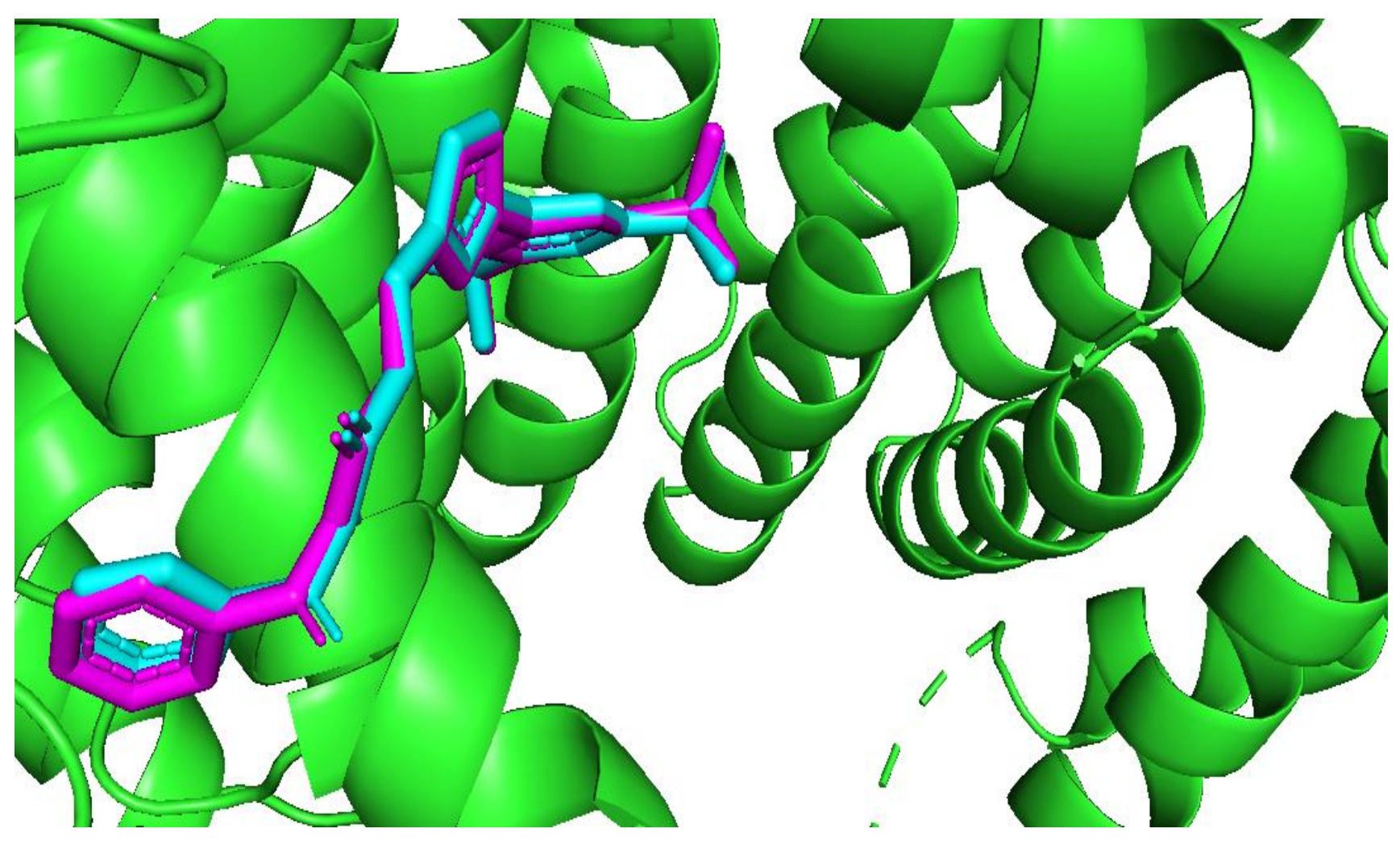

Figure 4: Superimposition of Ligands at the Exportin-1 Active Site

Table 4: Comparative Scores of Different Docking Algorithms with the Glide Docking Score

\begin{tabular}{|c|c|c|c|c|c|}
\hline Ligand/Algorithm & $\begin{array}{c}\text { PyRx } \\
\text { (kcal/mol) }\end{array}$ & $\begin{array}{c}\text { SwissDock } \\
\text { (kcal/mol) }\end{array}$ & $\begin{array}{c}\text { MVD } \\
\text { (Rerank } \\
\text { Score) } \\
\text { (kcal/mol) }\end{array}$ & $\begin{array}{c}\text { Argus } \\
\text { Lab } \\
\text { (kcal/mol) }\end{array}$ & $\begin{array}{c}\text { Glide MMGBSA } \\
\text { (dG) }\end{array}$ \\
\hline Eriodictyol & -6.7 & -7.87 & -89.6753 & -9.27391 & -40 \\
\hline KPT-185 & -6.1 & -7.23 & -105.158 & -7.53932 & -39.56 \\
\hline & & & & & \\
\hline
\end{tabular}




\subsection{Exportin-1-Ligand Interaction Study}

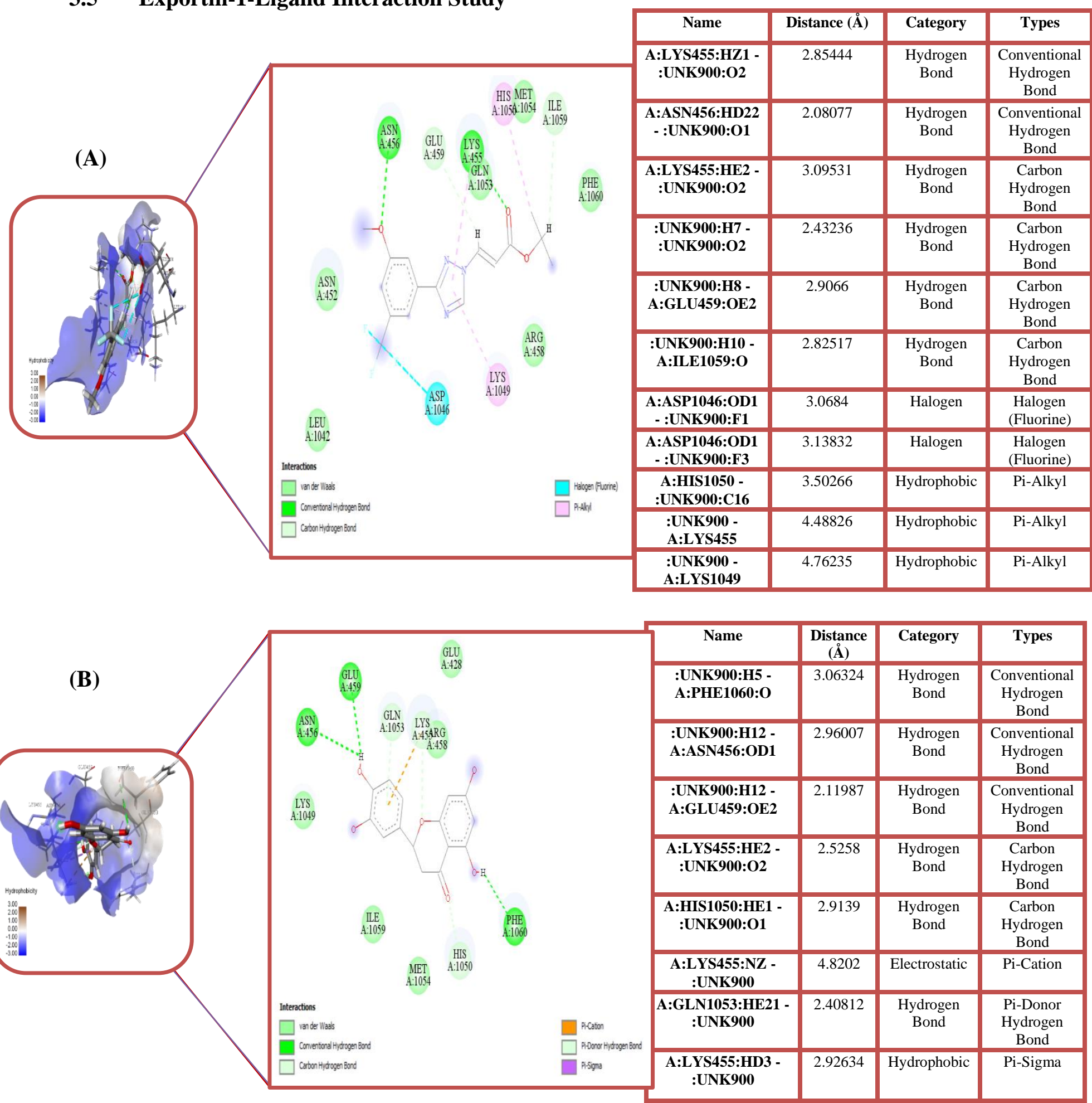

Figure 5: Representation of Ligand-Target Interaction. Figure shows (A) Interaction between KPT-185 and Exportin-1 (B) Interaction between Eriodictyol and Exportin-1 
The binding energy and, in consequence, efficacy of a drug entity at the target site is a function of nature and number of its interactions with the target residues. Examining the relative bonding interaction of the compounds and their prospective contribution to binding energy formation reveals eriodictyol formed relatively higher number of hydrogen interaction and fewer number of hydrophobic interactions at shorter bond distance to the target residues $(2.1199 \AA-3.0632 \AA$ of eriodictyol versus $2.0808 \AA-4.7624 \AA$ of KPT-185) than that of KPT-185. Notable exportin-1 active residue that shows conventional hydrogen bonding interaction with both compounds include Asn 456 and Glu 459 while eriodictyol formed carbon-hydrogen bond with additional hydrophobic (Pi-sigma) and electrostatic (Pi-cation) bond interaction instead with Lys 455 residue. The quantity and nature of hydrogen bonding interaction has been widely observed to have positive directional consequence for activity of drug entities (Patrick, 2013) and may have contributed to the relatively higher binding energy of eriodictyol.

\subsection{Density Functional Theory Property of Eriodictyol}

The characteristic quantum property of a molecular entity is the bedrock of its degree of chemical reactivity and stability (Braga et al., 2016). Estimating therefore the pivotal gap energy between the electron-donating site (HOMO) and the site of less resistance to electrophilicity in water solvation model of eriodictyol in this study (Table 4) revealed, through the Becke's threeparameter Lee-Yang-Parr correlation method, an equal value of its lowest excitation energies with that of KPT-185. However, it shows lower electrostatic potential energy in relative to KPT-185; a property defined by its degree of electron density cloud as shown in Figure 5D. This suggests relatively higher stability, with positive bearing toward ligand-receptor interaction, of eriodictyol than KPT-185 at the exportin-1 active site. 
Table 5: Density Functional Theory Properties Estimations of Eriodictyol

\begin{tabular}{|c|c|c|c|c|c|c|}
\hline Compound & $\begin{array}{c}\text { HOMO } \\
\text { Energy }\end{array}$ & $\begin{array}{c}\text { LUMO } \\
\text { Energy }\end{array}$ & $\begin{array}{c}\text { Gap } \\
\text { Energy }\end{array}$ & $\begin{array}{c}\text { Average } \\
\text { Ionization } \\
\text { Energy }\end{array}$ & $\begin{array}{c}\text { Electron } \\
\text { Density }\end{array}$ & $\begin{array}{c}\text { Electrostatic } \\
\text { Potential }\end{array}$ \\
\hline Eriodictyol & (A) -0.05 & (B) -0.05 & 0 & (C) 193.335 & 0.001 & (D) -49.3985 \\
\hline KPT-185 & (E) -0.05 & (F) -0.05 & 0 & (G) 196.049 & 0.001 & (H) -36.4269 \\
\hline
\end{tabular}

(A) Eriodictyol HOMO

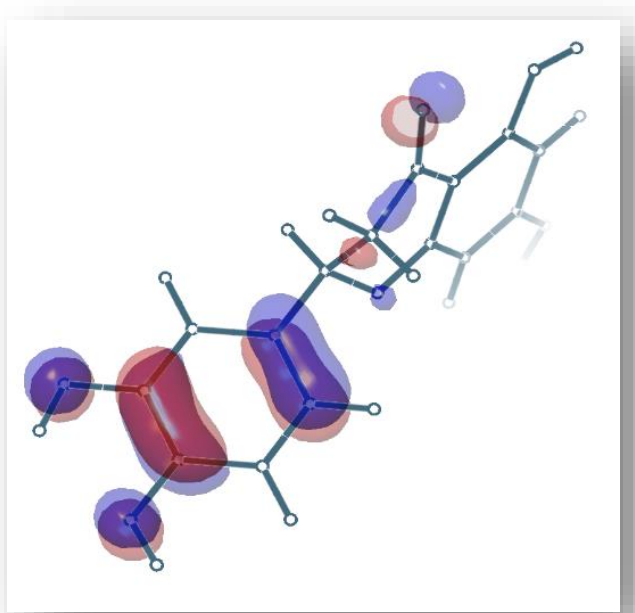

(C) Average Local Ionization Energy of Eriodictyol

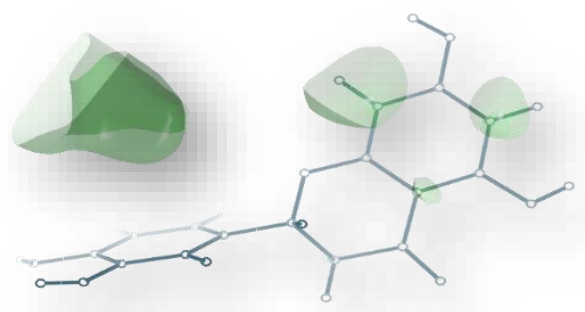

(B) Eriodictyol LUMO

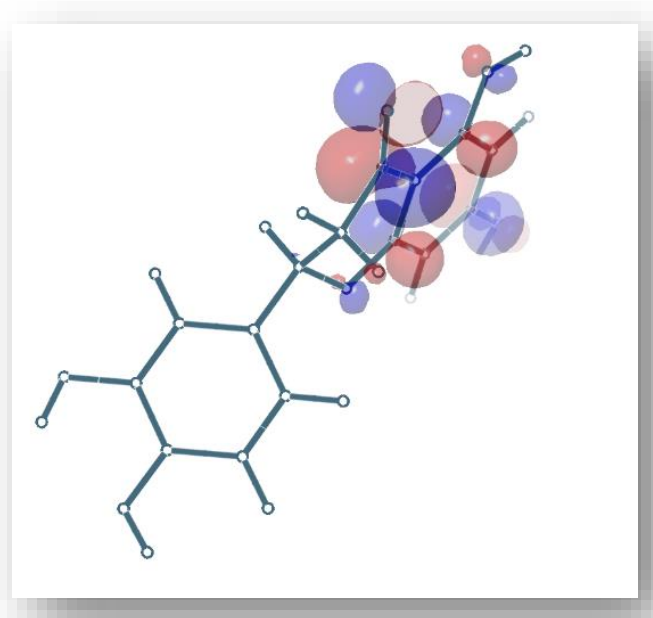

(D) Electrostatic Potential of Eriodictyol

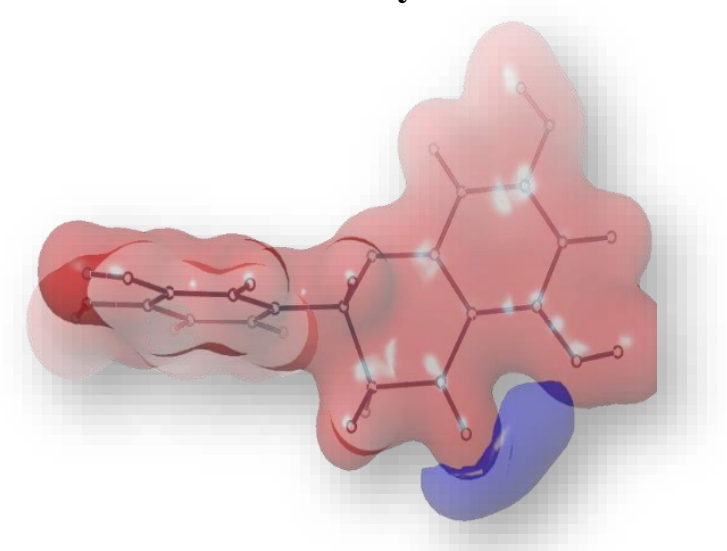


(E) KPT-185 HOMO

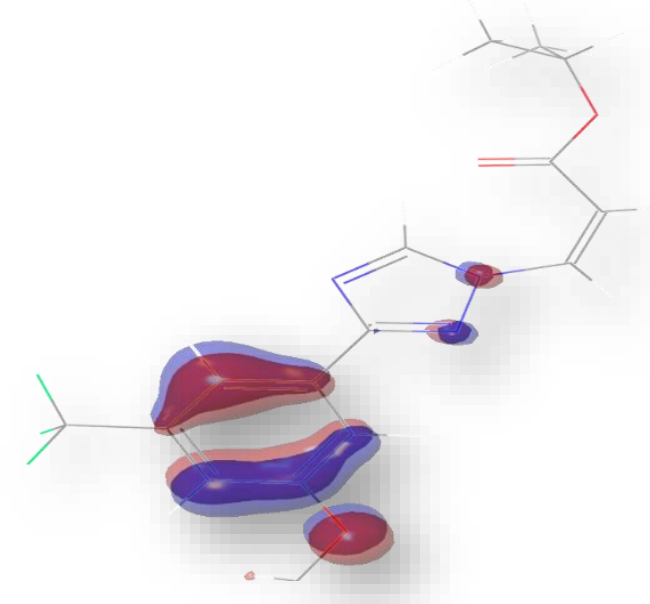

(G) Average Local Ionization Energy of KPT-185

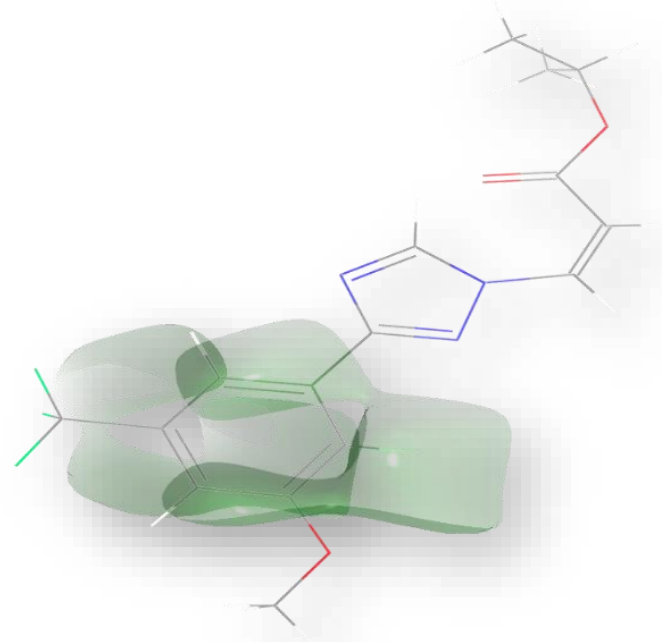

(F) KPT-185 LUMO

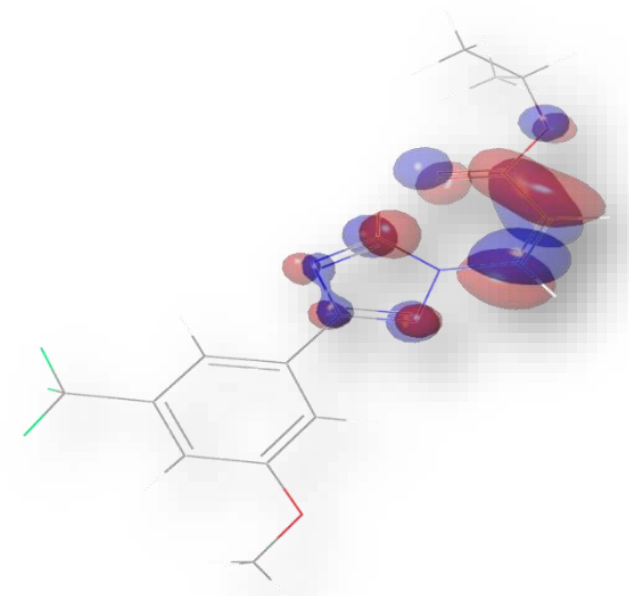

(H) Electrostatic Potential of KPT-185

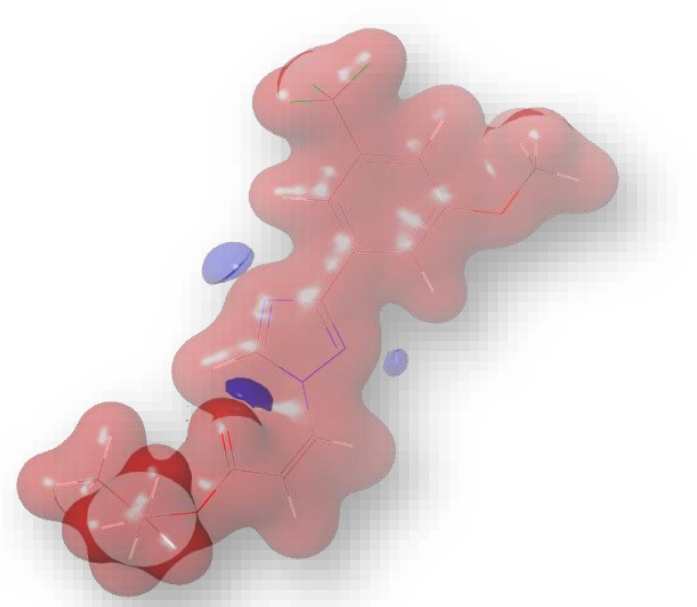

Figure 6: Density Functional Theory Properties of the Compounds 


\subsection{In-silico Pharmacokinetics and Toxicity Properties of Eriodictyol}

Better pharmacokinetic profile of a drug molecule positively associates with its good potency, biostability, and safety profile. This study reveals eriodictyol as predictively not inhibiting most of the commonly studied drug-metabolizing cytochrome P450 enzyme isoforms (Table 5); a property that may plausibly contributes toward adjusting dose-bioavailability balance of the drug molecule en route the site of action. Although eriodictyol is notably a potential inhibitor of Cytochrome P450 3A4 (an enzyme responsible for hepatic degradation of most drug compounds) in this study (Table 5); there is need to establish the comparative percentage probability at which both compounds are liable to metabolic action of this enzyme in order to estimate the relative stability indices of the compounds as well as predict their relative potential toward inducing drugdrug interaction en route to the action site. This is because maintaining pivotal balance between metabolic stability and potency of a drug molecule, in respect to avoidance of toxic metabolite production or reduced efficacy, is a vital feature of effective drug discovery and development (Daina et al., 2017).

The positive predictive gastrointestinal permeability of eriodictyol in this study (Table 5) may well associate with its positive calculated $\log \mathrm{P}$ value (Table 2) and thus shows its substantial lipophilicity potential as well as enhances its positive biological activity spectrum and selectivity potential.

Eriodictyol, unlike KPT-185, does not permeate the blood-brain barrier in this study (Table 5) but predictively a P-glycoprotein substrate. Both properties help in defining the possible biodistribution model of the compounds and while the former revealed the less possibility of eriodictyol, unlike KPT-185 (reported in some studies (Etchin et al., 2013; Azizian and Li, 2020), inducing any unintended central nervous system effect in the course of NSCLC therapy; the latter may help contribute to relative bioavailability and safety of the compound, though there is still a need to determine the relative percentage at which this occur en route to the target site.

The Brenk and PAINS filter of both eriodictyol and KPT-185 in this study (Table 5) shows both as not promiscuous, thereby excluding the possibility of any substructure with non-selective bioactive response but reveal KPT-185, unlike eriodictyol, as having putatively toxic, chemically reactive Michael acceptor substructure that may have contributed to its associated side effects in 
vivo. This led more credence to the potentially high safety and tolerability profile of eriodictyol as a putative exportin-1 inhibitor when compared to currently developed SINE compounds in the quest to develop better effective drug entity for NSCLC cure.

Table 6: Pharmacokinetics and Toxicity Profile of Eriodictyol

\begin{tabular}{|c|c|c|}
\hline Compound & KPT-185 & Eriodictyol \\
\hline GI absorption & High & High \\
\hline BBB permeant & Yes & No \\
\hline Pgp substrate & No & Yes \\
\hline CYP1A2 inhibitor & Yes & Yes \\
\hline CYP2C19 inhibitor & Yes & No \\
\hline CYP2C9 inhibitor & Yes & No \\
\hline CYP2D6 inhibitor & No & No \\
\hline CYP3A4 inhibitor & No & Yes \\
\hline HepG2 Cytotoxicity & No & No \\
\hline AMES & No & No \\
\hline MMP & No & No \\
\hline Brenk alert & 1 (Michael acceptor) & 0 \\
\hline PAINS alert & 0 & 0 \\
\hline
\end{tabular}




\subsection{Drug-likeness and Lead-likeness Evaluation of Eriodictyol}

The synthetic accessibility score of eriodictyol in this study (Table 6) shows that it contains, when compared to KPT-185, relatively higher frequent chemical moieties favourable for synthesis and low unfavourable rare moieties on a scale of 1 (easy to synthesized) to 10 (very difficult to synthesized). This presents eriodictyol as easy to synthesized for further preclinical and clinical evaluation.

Druglikeness and bioavailability are interdependent in determining the lead-likeness of a drug-like molecular entity (Teagle et al., 1999; Martin, 2005). The Abbot bioavailability score of both eriodictyol and KPT-185 in this study reveal both as highly Caco-2 cell permeable while the compounds obeys all rule of drug-likeness model (Table 6). The lead-likeness evaluation of both compounds reveals eriodictyol, unlike KPT-185 that is limited by molecular weight greater than 350, as a modifiable drug-like entity for its lipophilicity enhancement (Table 6) and, in consequence, potency increase.

Table 7: Druglikeness, Lead-likeness, and Synthetic Accessibility Score of Eriodictyol

\begin{tabular}{|c|c|c|}
\hline Compound & KPT-185 & Eriodictyol \\
\hline Bioavailability score & 0.55 & 0.55 \\
\hline Lipinski's violation & No & No \\
\hline Ghose's violation & No & No \\
\hline Veber's violation & No & No \\
\hline Egan's violation & No & No \\
\hline Muegge's violation & No & No \\
\hline Synthetic accessibility & 3.29 & 3.15 \\
\hline score & No $(1$ violation $)$ & Yes \\
\hline Lead-likeness & (MW > 350) & \\
\hline
\end{tabular}




\subsection{Conclusion}

The increasing global prevalence, associating morbidities, and the mortality rate of non-small cell lung cancer has rendered significant the discovery of new drug entity with better potency, pharmacokinetic, and safety profile in its chemotherapeutic approach. This study has revealed eriodictyol as a putative exportin-1 inhibitor with potentially better pharmaco-dynamo-kinetic properties than the current SINE compounds under pre-clinical and clinical studies. There is a need to further evaluate eriodictyol as a candidate exportin-1 inhibitor therefore in both pre-clinical and clinical studies involving lung cancer therapy.

\section{References}

Arteca GA (1993) Global Measure of Molecular Flexibility and Shape Fluctuations about Conformational Minima. Journal of Computational Chemistry 14 (6), 718-727 (CCC 0192-8651/93/060718-10)

Baell JB and Holloway GA (2010) New Substructure Filters for Removal of Pan Assay Interference Compounds (PAINS) from Screening Libraries and for their Exclusion in Bioassays. J. Med. Chem. 53, 2719-2740

Braga EJ, Corpe BT, Marinho MM, Marinho ES (2016) Molecular Electrostatic Potential Surface, HOMO-LUMO, and Computational Analysis of Synthetic Drug Rilpivirine. International Journal of Scientific \& Engineering Research 7 (7), 2229-5518

Brenk R, Schipani A, James D, Krasowski A, Gilbert IH, Frearson J, Wyatt GP (2008) Lessons Learnt from Assembling Screening Libraries for Drug Discovery for Neglected Diseases. Chem Med Chem 3, 435-444 (Doi: 10.1002/cmdc.200700139)

Daina A, Michielin O, and Zoete V (2017) SwissADME: A Free Web Tool to Evaluate Pharmacokinetics, Druglikeness and Medicinal Chemistry Friendliness of Small Molecules. Sci. Rep. 7, 42717 (Doi: 10.1038/srep42717)

Duan G, Ji C, and Zhang JZH (2020) Developing an Effective Polarizable Bond Method for Small Molecules with Application to Optimized Docking. RSC Adv. 10, 15530-15540 (Doi: 10.1039?DORA01483D)

Etchin J, Sun Q, Kentsis A, Farmer A, Zhang ZC, Sanda T, Mansour MR, Barcelo C, McCauley D, Kauffman M, Shacham S, Christie AL, Kung AL, Rodig SJ, Chook YM, and Look AT (2013) Anti-leukaemic Activity of Nuclear Export Inhibitors that Spare Normal Hematopoietic Cells. Leukemia 27, 66-74 (Doi: 10.1038/leu.2012.219)

Forrey C, Douglas JF, and Gilson MK (2012). The Fundamental Role of Flexibility on the Strength of Molecular Binding. Soft Matter 8 (23), 6385-6392 (Doi: 10.1039/C2SM25160D) 
Ghose AK, Viswanadhan VN, Wendoloski JJ (1999) A Knowledge-based Approach in Designing Combinatorial or Medicinal Chemistry Libraries for Drug Discovery. 1. A qualitative and quantitative characterization of known drug databases. J Comb Chem 1, 55-68

Lagorce D, Douguet D, Miteva MA, and Villoutreix BO (2017) Computational Analysis of Calculated Physicochemical and ADMET Properties of Protein-Protein Interaction inhibitors. Scientific Reports 7, 46277 (Doi: 10.1038/srep46277)

Lapalombella R, Sun Q, Williams K, Tangeman L, Jha S, Zhong Y, Goettl V, Mahoney E, Berglund C, Gupta S, Farmer A, Mani R, Johnson AJ, Lucas D, Mo X, Daelemans D, Sandanayaka V, Shechter S, McCauley D, Shacham S, Kauffman M, Chook YM, Byrd JC (2012) Selective inhibitors of nuclear export show that CRM1/XPO1 is a target in chronic lymphocytic leukemia. Blood 120 (23): 4621-4634 (Doi: 10.1182/blood-2012-05-429506)

Lipinski CA, Lombardo F, Dominy BW, Feeney PJ (2001) Experimental and Computational Approaches to Estimate Solubility and Permeability in Drug Discovery and Development Settings. Adv. Drug Deliv. Rev. 46 (1-3), 3-26

López-López E, Naveja JJ, and Medina-Franco JL (2019) DataWarrior: An Evaluation of the Open-source Drug Discovery Tool. Expert Opinion on Drug Discovery (Doi: 10.1080/17460441.2019.1581170)

Muegge I, Heald SL, Brittelli, D (2001) Simple Selection Criteria for Drug-like Chemical Matter. J. Med. Chem. 44 (12), 1841-1846

Patrick GL (2013) Drugs and Drug Targets: An Overview. An Introduction to Medicinal Chemistry Pp: 6-7 (Oxford University Press)

Santos MAB, Oliveira LFS, Figueiredo AF, Gil FS, Farias MS, Bitencourt HR, Lobato JRB, Martin YC (2005) A Bioavailability Score. J. Med. Chem. 48, 3164-3170

Teague S, Davis A, Leeson P, and Oprea T (1999) The Design of Lead-like Combinatorial Libraries. Angew. Chem. Int. Ed. Engl. 38, 3743-3748

Trbojević JB, Odović JV, Trbojević-Stanković JB, Nešić DM (2016) Relationship between the bioavailability and molecular properties of angiotensin II receptor antagonists. Archives of Biological Sciences 68 (2), 273-278 (Doi: 10.2298/ABS150915015T)

Veber DF, Johnson SR, Cheng HY, Smith BR, Ward KW, Kopple, KD (2002). Molecular properties that influence the oral bioavailability of drug candidates. J. Med. Chem. 45(12), 2615-2623

Wang AY and Liu H (2019). The past, present, and future of CRM1/XPO1 inhibitors. Stem Cell Investig 6: 6 